Article

\title{
Pd-Ag Electrical Resistivity in Hydrogen and Deuterium: Temperature Effect
}

\author{
Alfonso Pozio ${ }^{1, *}$ and Silvano Tosti ${ }^{2}$ \\ 1 Department of Energy Technologies, ENEA C.R. Casaccia, Via Anguillarese 301, S. Maria di Galeria, \\ 00123 Rome, Italy \\ 2 Department of Fusion and Technology for Nuclear Safety and Security, ENEA, C.R. Frascati, Via E. Fermi 45, \\ 00044 Frascati, Italy; silvano.tosti@enea.it \\ * Correspondence: alfonso.pozio@enea.it
}

Received: 19 September 2019; Accepted: 25 October 2019; Published: 29 October 2019

check for updates

\begin{abstract}
The electrical resistivity of Pd-Ag (silver $21 \mathrm{wt} . \%$ ) in hydrogen and deuterium atmosphere at $100 \mathrm{kPa}$ has been investigated via electrochemical impedance spectroscopy. The electrical resistivity of Pd-Ag vs. the temperature presents the characteristic S-shaped curve with a minimum and a maximum of the resistivity in different positions for the tests in hydrogen and deuterium. The results have been related to: (1) the different isotope ratios, $\mathrm{H} / \mathrm{M}$ and $\mathrm{D} / \mathrm{M}$, and (2) their position in the $\mathrm{Pd}-\mathrm{Ag}$ lattice. The behavior of the electrical resistivity is discussed in details by considering the hydrogen and deuterium uploading into the alloy, its effect on the conduction electrons, and the scattering of the isotopes atoms into the metal lattice. Measurements carried out in hydrogen with slow temperature ramping between $25-250{ }^{\circ} \mathrm{C}$ evidenced a hysteresis effect that can be explained by the different energy levels of isotopes in $\mathrm{O}$-sites and $\mathrm{T}$-sites
\end{abstract}

Keywords: Pd-Ag alloy; hydrogen; deuterium electrical resistivity

\section{Introduction}

Palladium-based membranes are studied for technological processes such as the separation and purification of hydrogen [1,2]. Potential applications concern the fusion fuel cycle where hydrogen isotopes have to be separated from plasma exhausts, from breeding blankets, and from coolants (water, helium) [3]. Several methods are proposed for recovering tritium from water [4-9] and, in particular, the use of membrane processes introduces the advantages of high reliability and continuous operations, ensuring the more efficient and safe management of a fusion power plant [10].

The uploading of hydrogen into pure Pd can involve metal embrittlement. In fact, at atmospheric pressure and below $300{ }^{\circ} \mathrm{C}$, the hydrogen is absorbed into $\mathrm{Pd}$ in two hydride phases $(\alpha$ and $\beta)$ characterized by different values of the lattice parameters $(0.3894$ and $0.4025 \mathrm{~nm}$, respectively): the transition between these two hydride phases involves cyclic strains of the lattice that are responsible for the embrittlement of hydrogenated Pd. The alloying of Pd with Ag [11,12] reduces the coexistence of the hydride phases $\alpha$ and $\beta$, thus reducing the hydrogen embrittlement. Ag alloying also improves the mechanical properties and hydrogen permeability [13]; both the tensile strength and the permeability show a maximum for silver content in the range $20 \%-40 \%$ of weight that is the Ag content of commercial Pd-alloys used for membrane applications. Also of note, the electrical resistivity of non-hydrogenated Pd-Ag alloys presents a maximum in the range 20-40 wt.\% of Ag loading [14]. Such a feature is of interest when the direct ohmic heating of Pd-permeators is deemed necessary. In this case, the temperature is controlled by powering the ends of a thin-walled Pd-Ag tube with electrical current [15]: the higher the electrical resistivity of the Pd-alloy, the lower the electrical current to be fed through these permeator tubes will be. The membrane units realized in this way make it possible to reduce the 
energy consumption and to speed up the heating, compared to conventional membrane modules [15]. Several literature works concern the effect of hydrogen isotopes on the properties of different Pd-alloys. These data are addressed especially on the analysis of mass transport parameters (diffusion, solubility, and permeability) in order to design process units for separation of hydrogen isotopes.

Kimura et al. [16] investigated the permeation of $\mathrm{H}_{2}$ and $\mathrm{D}_{2}$ through a Pd-Ag alloy in a low concentration range where the formation of $\mathrm{HD}$ was negligible. Mitsuishi et al. [17] studied the permeation of $\mathrm{H}_{2}, \mathrm{HD}$, and $\mathrm{D}_{2}$ for $\mathrm{H}_{2}-\mathrm{Ar}, \mathrm{D}_{2}-\mathrm{Ar}$, and $\mathrm{H}_{2}-\mathrm{D}_{2}-\mathrm{Ar}$ systems through a Pd-Ag-Au alloy tube at $400{ }^{\circ} \mathrm{C}$. Luo et al. [18] measured isotherms for $\mathrm{H}_{2} / \mathrm{D}_{2}-\mathrm{Pd}_{0.8} \mathrm{Ag}_{0.2}$ over a low temperature range, -75 to $50^{\circ} \mathrm{C}$. The H/D isotopic effect and the separation factors in the plateau range have been calculated and discussed along various isotherms.

Nishikawa et al. [19] performed permeation of hydrogen isotopes through a $\mathrm{Pd}_{0.75}-\mathrm{Ag}_{0.25}$ membrane in the temperature range 80 to $400{ }^{\circ} \mathrm{C}$ using the co-current double tube method by assessing the isotopic effect in permeation. The results showed that permeation is limited by diffusion of hydrogen atoms in the bulk of the membrane. Ackerman et al. [20] evidenced deuterium permeation lower than the hydrogen one through $\mathrm{Pd}_{0.75}-\mathrm{Ag}_{0.25}$ silver alloy tubes at driving pressures up to $100 \mathrm{kPa}$ and at temperatures of 300,400 , and $500{ }^{\circ} \mathrm{C}$.

Lasser et al. [21] evaluated the solubility of protium, deuterium, and tritium in palladium-silver alloys at low hydrogen concentrations. Furthermore, the ground state energies of hydrogen isotopes dissolved in these alloys have been determined. Paolone et al. [22] measured the hydrogen and deuterium solubility up to 7 bar for $\mathrm{Pd}_{0.77} \mathrm{Ag}_{0.23}$ in the temperature range between $25{ }^{\circ} \mathrm{C}$ and $400{ }^{\circ} \mathrm{C}$. In this work, the occurrence of solid solutions or hydride phases has been discussed and the hydrogenation enthalpy has been calculated. Anand et al. [23] measured equilibrium pressure-composition-temperature (PCT) relationships for $\mathrm{Pd}_{0.77}-\mathrm{Ag}_{0.23}$ over the temperature range of $101-146^{\circ} \mathrm{C}$, evaluating thermodynamic parameters like enthalpy and entropy of hydrogen/deuterium desorption reaction. Hydrogen/deuterium absorption for this alloy was investigated in the temperature range of $62-121^{\circ} \mathrm{C}$, and activation energies of hydrogen/deuterium absorption reactions were evaluated. Both thermodynamic and kinetic data showed pronounced normal isotopic effect in the temperature and pressure ranges investigated.

Hickman [24] measured solubility and permeability coefficients of deuterium in $\mathrm{Pd}_{0.75}-\mathrm{Ag}_{0.25}$ between 0 and $6900 \mathrm{kPa}$ at 300, 400, and $500{ }^{\circ} \mathrm{C}$. Deviations from ideal behavior have been observed, particularly for diffusion coefficients, so that permeability cannot be represented as a simple function of pressure. The non-ideality was attributed to the lattice expansion at high $\mathrm{D} / \mathrm{M}$ ratios. A strain-induced shift in solubility was also observed. Despite the large amount of works on this alloy, no data concerning the isotopic effect on electrical resistivity has been found in the literature. Few works exist on the effects of the Pd/hydrogen isotope interactions on electrical resistivity $[25,26]$.

The resistivity of a $\mathrm{Pd}_{1-\mathrm{x}}-\mathrm{Ag}_{\mathrm{x}}$ alloy in hydrogen has been studied in the past, showing a typical S-shaped curve as a function of $x(w t . \%)$, appearing for $x=10$ and disappearing completely at $\mathrm{x}=50$ [27-29].

In a previous work [30], the electrical resistivity of hydrogenated Pd-Ag (silver $21 \mathrm{wt} . \%$ ) has been measured in the temperature range $25-350{ }^{\circ} \mathrm{C}$ via electrochemical impedance spectroscopy. At a given hydrogen pressure, the electrical resistivity vs. the temperature exhibited the characteristic S-shaped curve with a minimum and a maximum of the resistivity. Such a behavior has been discussed, evaluating both the effect on the conduction electrons and the scattering of the $\mathrm{H}$ atoms in the metal lattice. Now, in the present study, we have extended electrochemical impedance spectroscopy to deuterium. The electrical resistivity vs. the temperature in deuterium presents similar S-shaped curves with the minimum and maximum of the resistivity in different positions. The behavior of the electrical resistivity has been discussed in details by considering the hydrogen and deuterium uploading, its effect on the conduction electrons, and the scattering of the isotope atoms into the metal lattice. Particularly, hydrogen occupancy of octahedral and tetrahedral sites (responsible for inverse 
and normal isotopic effects, respectively) is characterized by different energy levels that could explain the hysteresis of the resistivity curve observed at slow temperature ramping between $25-250{ }^{\circ} \mathrm{C}$.

\section{The Isotopic Effect on Pd-Ag Resistivity and Solubility}

To discuss experimental results, we must consider the isotopic effect on solubility and resistivity of hydrogenated Pd-Ag. In the first approximation, the $\mathrm{H}$ and $\mathrm{D}$ atoms in a metal lattice behave like independent simple harmonic or "Einstein" oscillators. Hydrogen and deuterium substitution can affect the vibrational frequency of the chemical bond that they form with the lattice, even if the potential energy surface for the reaction is nearly identical. Heavier isotopes (classically) lead to lower vibration frequencies or, viewed quantum mechanically, have lower zero-point energy (ZPV) [31]. The difference in zero-point vibration energies, $E_{v i b}$, between $H$ and $D$ is most likely to be the cause of isotopic effects. In the quantum harmonic oscillator approximation, vibrational energy is described by the Equation [32]:

$$
\mathrm{E}_{\mathrm{vib}}=\left(n+\frac{1}{2}\right) h v_{0}=\left(n+\frac{1}{2}\right) \frac{h}{2 \pi} \sqrt{\frac{K_{F}}{\mu}}
$$

where $n$ represents the energy level, $h$ is the Planck's constant, $v_{0}$ is the normal frequency of vibration, $K_{F}$ is the force constant, and $\mu$ is the reduced mass.

The frequency of the oscillations of the atoms can also be expressed using the Einstein temperature [33]:

$$
\theta_{\mathrm{E}}=\frac{h v_{0}}{k_{B}}
$$

where $k_{B}$ is the Boltzmann constant. Therefore, the lighter hydrogen isotope has the higher vibrational energy, $E_{v i b}(H)>E_{v i b}(D)$, or the higher $\theta_{E}$. With a lower zero-point energy (ZPV, $E_{v i b}$ for $\left.n=0\right)$, more energy must be supplied to break the bond, resulting in a higher activation energy for bond cleavage (Figure 1). As an example, to dissociate $\mathrm{H}_{2}$, it needs an energy of $431.7 \mathrm{~kJ} / \mathrm{mol}$ instead of $439.2 \mathrm{~kJ} / \mathrm{mol}$ for $\mathrm{D}_{2}$. When the only contribution was the loss of the zero point energy difference (i.e., complete failure of the bond), the expected isotopic effect should be about 1.41, having a frequency of vibration, $v_{0}$, of $4370 \mathrm{~cm}^{-1}$ for $\mathrm{H}_{2}$ and $3091 \mathrm{~cm}^{-1}$ for $\mathrm{D}_{2}$.

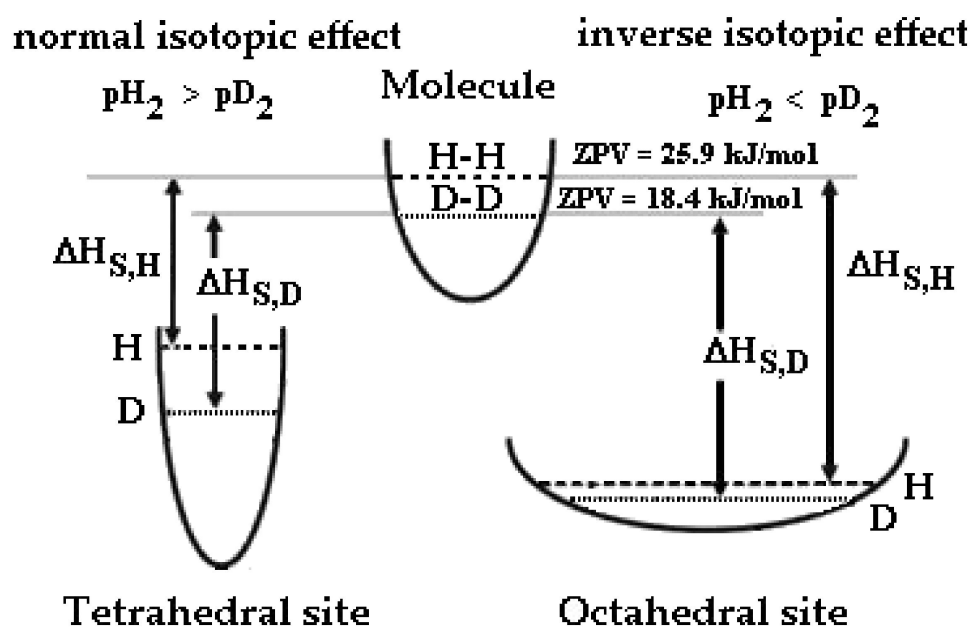

Figure 1. Schematic description of potential wells and zero-point vibration energies of $H$ and $D$ in a $\mathrm{H}_{2}$ and $\mathrm{D}_{2}$ molecule, octahedral and tetrahedral sites of Pd-Ag and isotopic effect on the enthalpy of solution, $\Delta \mathrm{H}_{\mathrm{S}}$.

We should consider the energy levels of deuterium and hydrogen inside the Pd-Ag lattice. Generally, in metals with a face-centered cubic structure (FCC) such as Pd-Ag hydrogen, isotopes 
occupy mainly octahedral sites (O-sites), as the volume space of O-sites is larger than that of T-sites [34,35].

Since the $K_{F}$ of hydrogen isotopes in O-sites is smaller than that in T-sites, the shape of the potential wall in the O-sites is smooth (Figure 1). The different potential energy profiles give rise to a very different ZPV of hydrogen in T-sites $(\sim 150 \mathrm{meV})$ with respect to octahedral site $(\sim 60 \mathrm{meV})$ [36-38].

Now, we should consider that the absolute level energy for the enthalpy follows the trend $\left|\Delta \mathrm{H}_{\mathrm{S}, \mathrm{H}} \mathrm{O}\right|$ $>\left|\Delta \mathrm{H}_{\mathrm{S}, \mathrm{D}} \mathrm{O}\right|>\left|\Delta \mathrm{H}_{\mathrm{S}, \mathrm{D}}{ }^{\mathrm{T}}\right|>\left|\Delta \mathrm{H}_{\mathrm{S}, \mathrm{H}}{ }^{\mathrm{T}}\right|$, for this reason, different equilibria can occur when we upload hydrogen isotopes into a metal at different temperatures. It is noteworthy that the absorption enthalpy is negative, so for the hydrogenated Pd-Ag the lowest enthalpy is that of $\mathrm{H}$ in O-sites. In order to highlight the different isotopic behavior into a Pd-Ag lattice, we can establish that: (1) the absolute enthalpy solution of both isotopes in the O-sites is lower than in T-sites, and (2) in O-sites, the absolute enthalpy solution of hydrogen is lower than the deuterium one (and vice versa for T-sites).

At room temperature and high pressure (namely, high hydrogen uploading levels), all sites $\mathrm{T}$ and $\mathrm{O}$ of the Pd-Ag lattice are occupied so that no significant differences of chemical-physical properties can be observed between the hydrogenated and deuterated metal. By increasing the temperature (i.e., by providing thermal energy to the system), first, hydrogen leaves the T-site, having the lowest enthalpy, followed by deuterium from the T-site, then deuterium from the O-site and finally hydrogen from the O-site.

According to the definition given in the literature [22,36], when tetrahedral sites are occupied (low temperature), the $\mathrm{Pd}-\mathrm{Ag}-\mathrm{H}$ system exhibits a normal isotopic effect (i.e., the equilibrium pressure of hydrogen isotopes in gas and solid phases is $\mathrm{pH}_{2}>\mathrm{pD}_{2}$ ), while at high temperature (octahedral occupancy), an inverse isotopic effect occurs $\left(\mathrm{pD}_{2}>\mathrm{pH}_{2}\right)$. In general, $\mathrm{Pd}-\mathrm{Ag}$ is expected to exhibit an inverse isotopic effect due to the occupancy of the O-sites; however, at high uploading (low temperature and high pressure), the T-sites are also occupied and the Pd-alloys shows a normal isotopic effect. In practice, the Pd-Ag alloy exhibits a completely different behavior when hydrogenated at low or high $\mathrm{H} / \mathrm{M}(\mathrm{D} / \mathrm{M})$ ratios: similar behavior (occupancy of $\mathrm{O}-$ and T-sites with inversion of the isotopic effect) has been observed for $\mathrm{V}-\mathrm{H}$ and Ti-H systems [36].

Vacuum experiments dedicated to measuring the hydrogen absorption temperature [39] confirmed that, by increasing the temperature, the equilibrium tetrahedral $\leftrightarrow$ octahedral shifts toward the right. We can presume that the same equilibrium exists for deuterium:

$$
\begin{aligned}
& H_{\mathrm{T}} \leftrightarrow H_{O} \\
& D_{\mathrm{T}} \leftrightarrow D_{O}
\end{aligned}
$$

where subscripts indicates $\mathrm{O}$ e T-sites.

In particular, we can observe that the difference, $\left|\Delta \mathrm{H}_{\mathrm{S}, \mathrm{H}} \mathrm{O}_{\mid}-\right| \Delta \mathrm{H}_{\mathrm{S}, \mathrm{H}}{ }^{\mathrm{T}} \mid$, is higher than $\mid \Delta \mathrm{H}_{\mathrm{S}, \mathrm{D}} \mathrm{O}^{\mathrm{O}}-$ $\left|\Delta \mathrm{H}_{\mathrm{S}, \mathrm{D}} \mathrm{T}\right|$ and, therefore, the presence of the hysteresis phenomena (H or D occupancy, resistivity, etc.) should be observed through a slow adsorption/desorption (i.e., under quasi-equilibrium conditions) of hydrogen and deuterium. Indeed, heating and cooling hydrogenated Pd-Ag means a shift in equilibrium (3) and (4), but being that thermal energy for hydrogen adsorption/desorptionm is higher than that of deuterium, any hysteresis should be higher for hydrogen. This phenomenon will be presented in the last part of the Results section.

In order to discuss the isotopic effect on $\mathrm{H}$ and $\mathrm{D}$ solubility, it is opportune to define some parameters. The atoms of hydrogen isotopes per atom of metal, H/M (D/M) ratio, can be calculated from the solubility $s\left(\mathrm{~mol} \mathrm{~m}^{-3}\right)$ with the relationship [29]:

$$
\frac{H(D)}{M}=\frac{2 \times s \times P M_{P d-A g}}{d \times 0.79}
$$

where $P M_{P d-A g}$ is the molecular weight of the alloy, $d$ is the Pd-Ag $21 \mathrm{wt} . \%$ density $\left(11,600 \mathrm{~kg} \mathrm{~m}^{-3}\right)$, and 0.79 is the atomic percent of Pd into the Pd-Ag alloy. 
Under equilibrium conditions, the hydrogen (or deuterium) solubilized in the metal, $s$, and its partial pressure, $p(\mathrm{~Pa})$, in the gaseous phase is expressed through Sieverts' law by the equation $[19,40,41]$ :

$$
\begin{aligned}
& s\left(H_{2}\right)=K_{H} p^{0.5} \\
& s\left(D_{2}\right)=K_{D} p^{0.5}
\end{aligned}
$$

where $K_{H}$ and $K_{D}\left(\mathrm{~mol} \mathrm{~m}^{-3} \mathrm{~Pa}^{0.5}\right)$ are the solubility constants for the two isotopes. They are a function of temperature according to an Arrhenius-type equation:

$$
\begin{gathered}
K_{H}=A \times e^{B / R T}=0.182 \exp \left(\frac{19598}{R T}\right) \\
K_{D}=A \prime \times e^{B^{\prime} / R T}=0.184 \exp \left(\frac{18531}{R T}\right)
\end{gathered}
$$

where $A, A^{\prime}, B, B^{\prime}$ are empirical constants obtained by gas permeation experiments $[19,40,41], R=$ $8.314 \mathrm{~J} \mathrm{~K}^{-1} \mathrm{~mol}^{-1}$, and $T$ is the temperature $(K)$. From the above equations, at constant pressure we can write the ratio $\beta(\mathrm{H} / \mathrm{D})$ of solubilities $\mathrm{s}\left(\mathrm{H}_{2}\right) / \mathrm{s}\left(\mathrm{D}_{2}\right)$ of hydrogen isotopes through Pd-Ag membranes as $[19,40,41]$ :

$$
\beta(H / D)=0.989 \exp \left(\frac{1067}{R T}\right)
$$

This expression calculates the $\mathrm{D} / \mathrm{M}$ ratio from the corresponding $\mathrm{H} / \mathrm{M}$ when Sieverts' law is valid (i.e., pressure lower than $100 \mathrm{kPa}$ and temperature higher than $200{ }^{\circ} \mathrm{C}$ ). In contrast, at $100 \mathrm{kPa}$ and a temperature lower than $200{ }^{\circ} \mathrm{C}$, Sieverts' law cannot be applied and Equations (6) and (7) assess solubility values lower than those experimentally measured. In the literature, the analysis of pressure composition isotherms [18,21-23] showed a sloping-plateau region distinct for $\mathrm{H}_{2}$ and $\mathrm{D}_{2}$. It is also evident that deuterium equilibrium pressure is higher than that of hydrogen at all experimental temperatures because of an inverse isotopic effect $\left(\mathrm{pD}_{2}>\mathrm{pH}_{2}\right)$. At the same time, all measurements showed that at high pressure, $\geq 100 \mathrm{kPa}$, as the temperature is reduced towards room temperature the difference of $\mathrm{H} / \mathrm{M}$ and $\mathrm{D} / \mathrm{M}$ reduces also.

In this study, both H/M [22,30,40,42-44] and D/M [18,21-23,31,45] were extrapolated by literature data on the same kind of alloy in order to compare solubility with resistivity data. The literature evidenced that at $100 \mathrm{kPa}$ for low temperatures $\left(25-70^{\circ} \mathrm{C}\right)$ the $\mathrm{D} / \mathrm{M}$ approaches the $\mathrm{H} / \mathrm{M}$ value, while increasing the temperature $\left(75-200^{\circ} \mathrm{C}\right)$ causes the $\mathrm{D} / \mathrm{M}$ to decreases faster, and only at high temperature $\left(>30{ }^{\circ} \mathrm{C}\right)$ do both curves $(\mathrm{H}$ and $\mathrm{D})$ tend to converge to very low values (close to zero).

As introduced above, the isotopic mass affects not only the concentration of hydrogen/deuterium into the metal lattice at a given temperature and pressure but also the composition-temperature boundaries between solid phases. The physical reasons for the effect of isotopic mass on phase boundaries are related to differences in the zero-point energies of the dissolved isotopes, the differences in the lattice expansions produced by the isotopes, and the differences produced in the phonon spectrum $[32,46]$.

Electrical resistivity is also influenced by these effects because it depends on phonon scattering that is strictly related to the vibrational energy of isotopes in T- and O-sites [33,47]. Solids as Pd-Ag can exhibit two types of phonon scattering: acoustic phonons and optical phonons. Acoustic phonons are coherent movements of atoms in the lattice out of their equilibrium positions. Optical phonons are out-of-phase movements of the atoms in the lattice (i.e., one atom moving to the left and its neighbor to the right). Electron scattering centers are produced in metal hydrides when interstitial vacancies are occupied by $\mathrm{H}$ or $\mathrm{D}$, producing a new optical phonon band. Smith et al. [26] observed that, for similar concentration of isotopes, $\mathrm{Pd}-\mathrm{H}$ shows lower resistivity than Pd-D. They justified this behavior by claiming that a major change to the phonon spectrum with the addition of deuterium is the introduction of a band of optic modes. Tsuchiya et al. [48] and Bickel et al. [49] also observed lower electrical 
resistivities of hydrogenated $\varepsilon-\mathrm{Zr}$ at 25 and $325^{\circ} \mathrm{C}$ : such a behavior was considered to be related to the electron-phonon scattering, where the optical mode plays an important role.

\section{Experimental Methods}

The resistivity measurements were performed in four-electrode AC impedance mode using a Solartron 1260 frequency response analyzer by Schlumberger. The spectra were recorded between 1 $\mathrm{Hz}$ and $150 \mathrm{kHz}$ with 10 points per decade and a maximum perturbation amplitude of $0.5 \mathrm{~mA}$.

The metal sample consisted of a $21 \%$ by weight Pd-Ag thin strip of $141.0 \mathrm{~mm}$ length, $4.4 \mathrm{~mm}$ width, and $51 \mu \mathrm{m}$ of thickness: it was obtained by the cold rolling of a commercial sample (Good Fellows). This sample had been located in a gas-tight stainless steel vessel while four parallel platinum electrical contacts were welded to the ends of the metal strip. In particular, the length (l) of the Pd-Ag strip between the voltage measurement points was $137.5 \mathrm{~mm}$. The impedance in the tangential direction (in the plane) of the lamina was measured, and its resistivity was obtained using the equation:

$$
\rho=\frac{R_{\Omega} \times A}{l}
$$

where $\rho, l, R_{\Omega}$, and A denote the resistivity $(\Omega \mathrm{m})$, the distance between the probe $(\mathrm{m})$, the measured resistance $(\Omega)$, and the cross-sectional area $\left(\mathrm{m}^{2}\right)$ of the sample Pd-Ag, respectively. The area, $A$, was calculated from the product of the thickness of the Pd-Ag strip $(r)$ by its width $(h)$.

The sealed stainless steel module, provided with a gas inlet and outlet, was equipped with an electric heating apparatus based on temperature measurements carried out by two thermocouples (Figure 2). The module was thermally insulated and reduced in size in order to guarantee a homogeneous temperature along the entire volume.

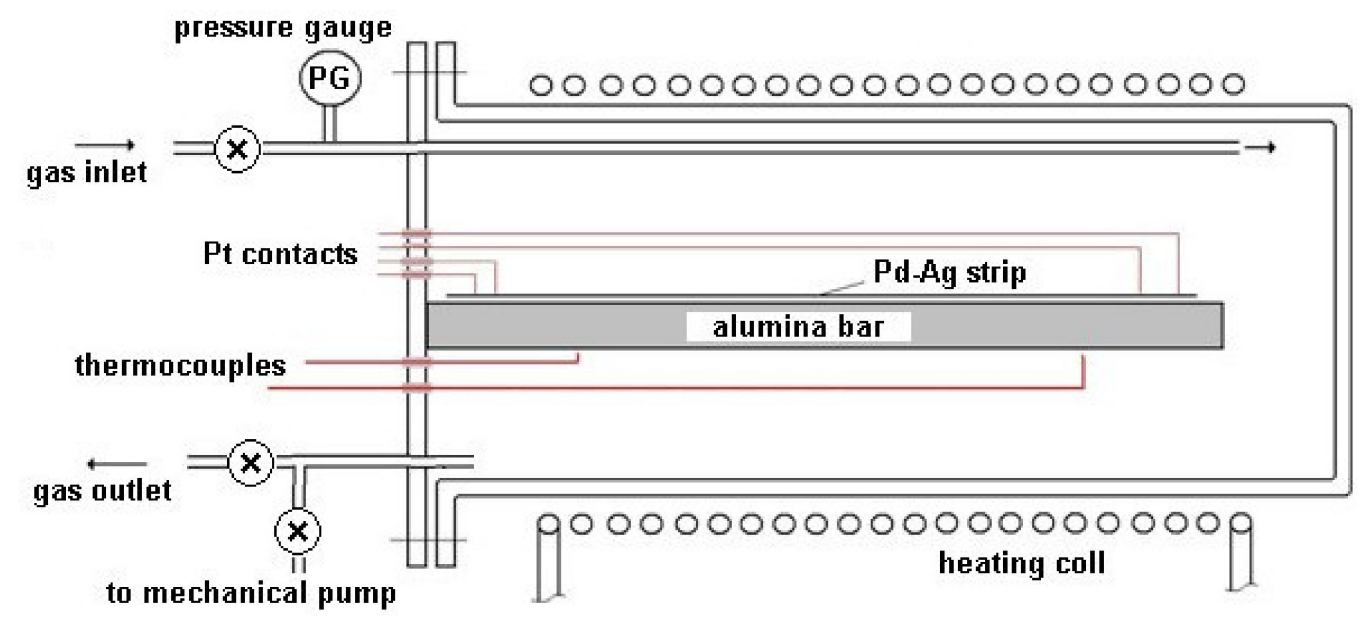

Figure 2. Experimental apparatus.

Values of temperature and resistivity were recorded continuously during the tests. The experiments focused on the study of the electrical resistivity behavior of hydrogenated and deuterated Pd-Ag. The experimental campaign has been carried out in the range $25-450^{\circ} \mathrm{C}$ under $\mathrm{Ar}, \mathrm{H}_{2}$, and $\mathrm{D}_{2}$ atmospheres at $100 \mathrm{kPa}$. The first experiments were performed with a heating ramp of $5^{\circ} \mathrm{C} / \mathrm{min}$, while the following tests were at $1{ }^{\circ} \mathrm{C} / \mathrm{min}$.

\section{Results and Discussion}

\subsection{Electrical Resistivity vs. Temperature}

The dependence of the electrical resistance of metals on temperature, $\rho_{T}$, is generally described by the linear equation [50]:

$$
\rho_{T}=\rho^{\circ}\left[1+\alpha\left(T-T^{\circ}\right)\right]
$$


where $T$ and $T^{\circ}$ are the temperature and the reference temperature (usually room), $\rho^{\circ}$ is the resistivity at reference temperature $T^{\circ}$, and $\alpha$ is the so called thermal coefficient (the variation of resistivity per unit of temperature).

For a limited temperature range, the value of $\alpha$ can be assumed in the first approximation to be constant and dependent on the metal examined. Equation (12) is valid for non-hydrogenated material; in particular in argon, the resistivity relation vs. temperature for Pd-Ag $21 \mathrm{wt} . \%$ was almost linear in the range $25-450{ }^{\circ} \mathrm{C}$, and the $\alpha$ value was about $4.4 \times 10^{-4}{ }^{\circ} \mathrm{C}^{-1}$. In this work, the Pd-Ag resistivity, $\rho^{\circ}$, at $25^{\circ} \mathrm{C}$ in argon was $3.9 \times 10^{-7} \Omega \mathrm{m}$.

When the metal is hydrogenated or deuterated, the resistivity depends on the amount and kind of isotopes, gas pressure, and operating temperature [29]. Figure 3 shows the ratio $\rho / \rho^{\circ}$ resistivity vs. temperature at $100 \mathrm{kPa}$ in hydrogen and deuterium compared with the trend in argon. Figure 3 highlights the relationship between $\rho / \rho^{\circ}$ and temperature in hydrogen, deuterium, and argon at a pressure of $100 \mathrm{kPa}$.

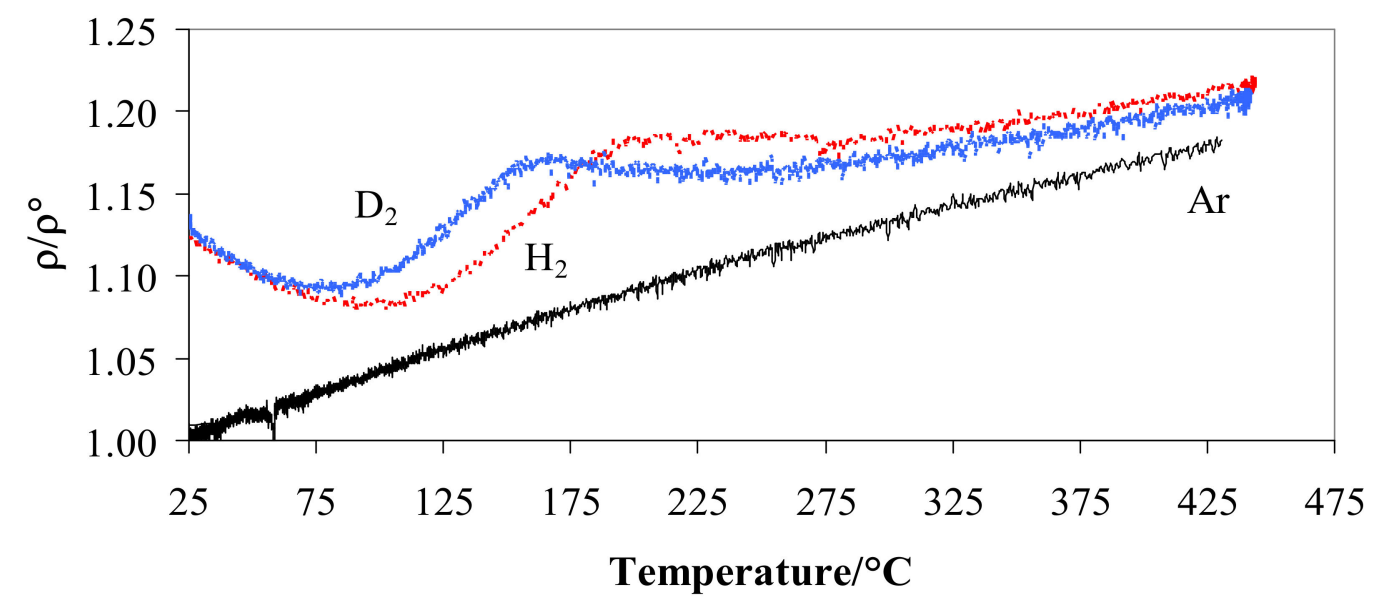

Figure 3. Ratio $\rho / \rho^{\circ}$ vs. temperature for Pd-Ag 21 wt. $\%$ in pure hydrogen, deuterium, or argon at $100 \mathrm{kPa}$.

Figure 3 shows that, at the room temperature, $\mathrm{Pd}-\mathrm{Ag} / \mathrm{H}$ and $\mathrm{Pd}-\mathrm{Ag} / \mathrm{D}$ have a similar resistance $\left(4.4 \times 10^{-7} \Omega \mathrm{m}\right)$ with a value greater than 1.13 compared to that of the alloy without the isotopes $(3.9 \times$ $10^{-7} \Omega \mathrm{m}$ ). As the temperature increased, a minimum at $\mathrm{T} \approx 85-90^{\circ} \mathrm{C}$ was reached for the deuterated alloy, while the hydrogenated material showed the minimum at a higher temperature $\left(95-105^{\circ} \mathrm{C}\right)$. Above $250{ }^{\circ} \mathrm{C}$, the ratio tends to increase slowly for both systems but at the same speed.

\subsection{Electrical Resistivity vs. Hydrogen Isotopic Content}

The lattice imperfections that can increase electrical resistivity are of two kinds: (i) thermal vibrations and ii) impurities and other punctual defects. In a metal alloy like Pd-Ag, lattice vibrations diminish as the temperature decreases: therefore, we assume that their effect on resistivity will modify according to Equation (12).

The total resistivity can be defined for Pd-Ag hydrogenated with $\mathrm{H}$ or D as the sum of two terms [51]:

$$
\rho=\rho_{T}+\rho_{i}
$$

where $\rho_{T}$ is the resistivity produced solely by the thermal vibration of the Pd-Ag lattice without $\mathrm{H}$ atoms; such a parameter increases with temperature as outlined by Equation (12). As regards the second term, $\rho_{i}$, it is a complex contribution linked to different effects. The interstitial atoms H (D) influence the electrical resistance of the host metal [50]: their existence in the lattice can be supposed to provide, in part, a second type of lattice imperfection that rises with the amount of $\mathrm{H}(\mathrm{D})$ atoms. $\rho_{i}$ certainly includes a structural resistivity due to impurity scattering of electrons on interstitial protons 
or vacancies. This term is also connected to electron-phonon scattering due to the vibration of $\mathrm{H}$ and $\mathrm{D}$ in the lattice: the larger the intensity of vibration at any temperature, the greater the $\rho_{i}$ is. So, this term depends on several parameters: $H$ (D) concentration into the lattice, temperature, position of $H$ (D) atoms, and their interaction with metal sites. In addition, these different parameters can depend upon each other.

As shown, non-hydrogenated Pd-Ag $\rho_{T}$ increases with temperature. Combining Equations (12) and (13), we can formalize the contribution of resistivity produced only by the presence of hydrogen or deuterium through the equation:

$$
\rho_{\mathrm{i}}=\rho-\rho^{\circ}\left[1+\alpha\left(T-T^{\circ}\right)\right]
$$

From a graphic point of view, we can visualize $\rho_{i}$ by subtracting the resistivity measured in pure hydrogen or deuterium from that in argon (Figure 4).

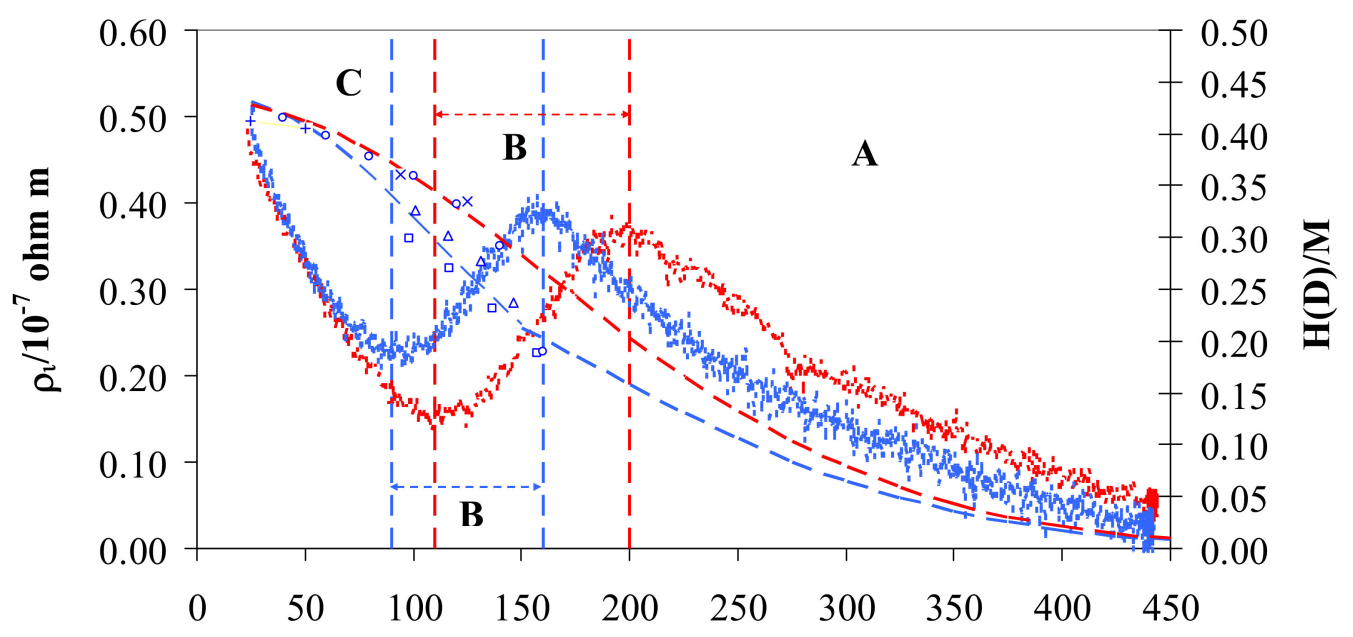

Temperature $/{ }^{\circ} \mathrm{C}$

Figure 4. $\rho_{i}$ vs. temperature for Pd-Ag $21 \mathrm{wt} . \%$ in pure hydrogen (red) and deuterium (blue) and relative $\mathrm{H} / \mathrm{M}$ (red) and D/M (blue) values at $100 \mathrm{kPa}$. The literature data for D/M: (+) [18], (○) [21], $\times[22],(\triangle)[23],(\square)[45]$ are also shown. Vertical dashed lines show the limits for the different regions $\mathrm{A}$, $\mathrm{B}$, and $\mathrm{C}$ in pure hydrogen (red) and deuterium (blue).

The resistivity behavior exhibits the same S-shaped trend for hydrogen and deuterium. Particularly, the two curves overlap in the range $25-70{ }^{\circ} \mathrm{C}$ (contributing $11 \%$ of total resistivity) and both curves show a maximum and a minimum with two relevant differences: (i) the minimum and maximum are, respectively, at about 90 and $160{ }^{\circ} \mathrm{C}$ in $\mathrm{D}_{2}$ and at 110 and $200{ }^{\circ} \mathrm{C}$ in $\mathrm{H}_{2}$, (ii) maxima of resistivity are the same for $\mathrm{D}_{2}$ and $\mathrm{H}_{2}$, and (iii) minimum of resistivity in $\mathrm{D}_{2}$ is higher than in $\mathrm{H}_{2}$.

Figure 5 depicts the resistivity isotopic effect expressed as the ratio of the values for hydrogen and deuterium, $\rho_{i}$, (left-axis) and their differences (right-axis). The isotopic effect on resistivity expressed by $\rho_{i}$ is negligible at low temperature $\left(\rho_{i}\right.$ is close to 1$)$ but, at about $70^{\circ} \mathrm{C}$, the effect becomes negative $\left(\rho_{i}^{\mathrm{D}}>\rho_{i}{ }^{\mathrm{H}}\right)$, and after the minimum at $125{ }^{\circ} \mathrm{C}$ it increases again, being positive over $160{ }^{\circ} \mathrm{C}\left(\rho_{i}{ }^{\mathrm{H}}>\rho_{i}{ }^{\mathrm{D}}\right)$, achieving a maximum value of 1.41 at about $250^{\circ} \mathrm{C}$ and then decreasing above this temperature to a constant value (1.20). 


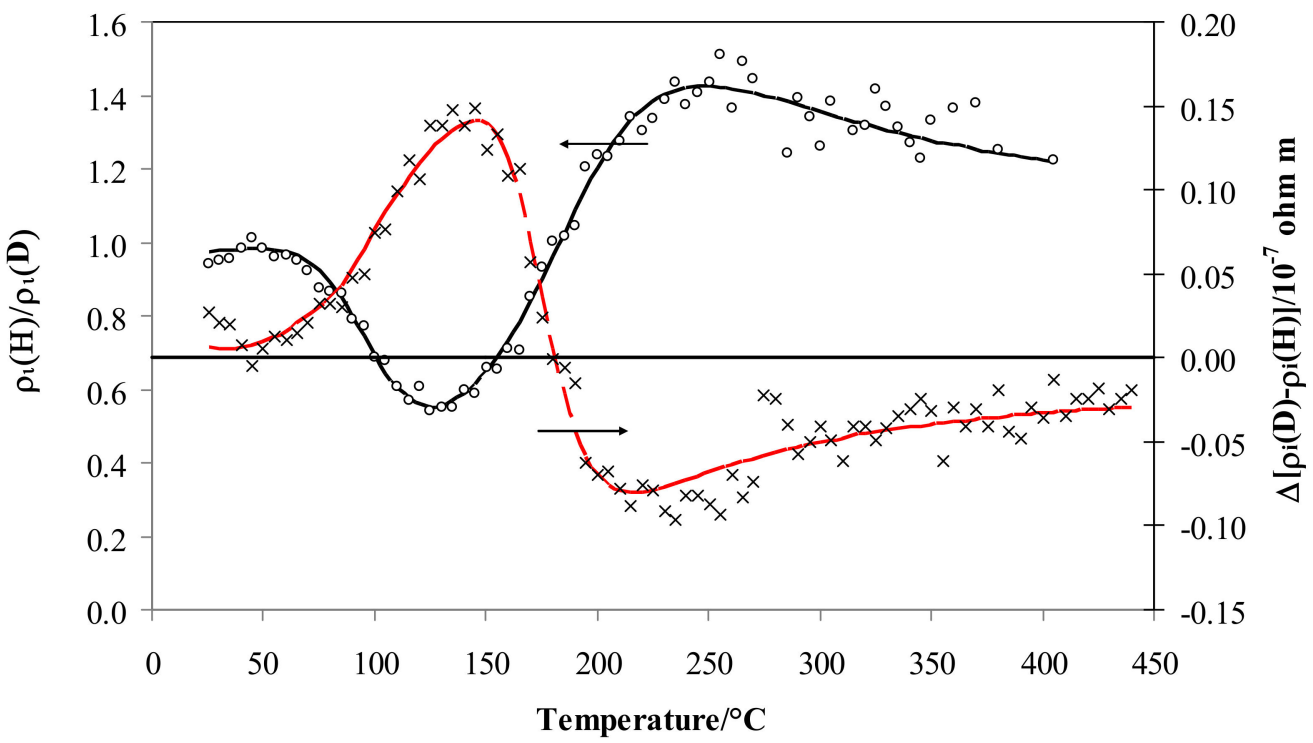

Figure 5. Ratio of $\rho_{i}$ vs. temperature for Pd-Ag $21 \mathrm{wt} . \%$ in pure hydrogen and deuterium (black) and the difference in deuterium less hydrogen (red).

In previous works, the characteristic S-shape for Pd-Ag in hydrogen was explained through the free electrons theory $[30,39]$ : here in this study, the previous analysis is extended to deuterium. In general, three regions were observed when reducing temperature from 450 to $25^{\circ} \mathrm{C}$; (i) region A below $450{ }^{\circ} \mathrm{C}$, where the resistivity, $\rho_{i}$, increased until a maximum was reached, (ii) region $\mathrm{B}$, where a decrease of resistivity was observed until a minimum was achieved, and (iii) region $C$, with a continuous increase of resistivity. The limits in temperature of these three regions are different in hydrogen and deuterium, being related to the $\mathrm{H} / \mathrm{M}$ and $\mathrm{D} / \mathrm{M}$ ratio (Figure 4).

The first $\mathrm{H}$ or $\mathrm{D}$ atoms uploaded into $\mathrm{Pd}_{0.79}-\mathrm{Ag}_{0.21}$ diminish the number of metal valence electrons $(N)$ thus raising the resistivity, $\rho_{i}$ (region A in Figure 4). This process ends when the electrons fill all of the valence band: it occurs at a well-defined value of $\mathrm{H} / \mathrm{M}$, calculated so that the sum of $\mathrm{H} / \mathrm{M}+0.21(\mathrm{Ag})$ achieves about $40 \%[40,52,53]$. This is confirmed in hydrogen, where we observe the $\mathrm{H} / \mathrm{M}$ maximum around 0.20 at $200{ }^{\circ} \mathrm{C}$. Furthermore, it is known that, before the d-band is filled, all these hydrogen atoms occupy octahedral interstitial positions. The trend of the resistivity in deuterium was generally quite similar to the hydrogen one, being the differences due to different values of uploading $(\mathrm{H} / \mathrm{M}$ vs. $\mathrm{D} / \mathrm{M})$ along the temperature. The maximum of resistivity in deuterium was shifted at about $160{ }^{\circ} \mathrm{C}$ (Figure 4): in fact, at this temperature, $\mathrm{D} / \mathrm{M}$ reaches a value of about 0.20 . The values of maximum resistivity in hydrogen and deuterium are quite similar (about $0.4 \times 10^{-7} \Omega \mathrm{m}$ ): as discussed above, it is noteworthy that these maxima occur with the same occupancy of the isotopes inside the Pd-Ag $(\mathrm{H} / \mathrm{M}$ and $\mathrm{D} / \mathrm{M}=0.20)$. Further absorption of hydrogen (region B in Figure 4$)$ determines a growth of $\mathrm{N}$ (number of conduction electrons per unit volume) and, hence, a decreasing of resistivity, $\rho_{i}$, down to a minimum $\left(0.15 \times 10^{-7} \Omega \mathrm{m}\right)$ with $\mathrm{H} / \mathrm{M}$ of about 0.34 at $110^{\circ} \mathrm{C}$. We also reach, in deuterium, the minimum of resistivity (but at a higher value of $0.23 \times 10^{-7} \Omega \mathrm{m}$ ) for quite a similar value of uploading $(\mathrm{D} / \mathrm{M}=0.34)$ at $90^{\circ} \mathrm{C}$. The electrical resistivity of $\mathrm{Pd}-\mathrm{Ag}$, higher in deuterium than in hydrogen at the same ratio (0.34), can be interpreted by the progressive excitation of optical vibration modes $[26,48]$. In fact, optical vibrations depend on thermal energy, and it is reasonable to expect that the position and energy of $\mathrm{D}$ and $\mathrm{H}$ in $\mathrm{O}$ - and T-sites in the lattice of $\mathrm{Pd}-\mathrm{Ag}$ is responsible for their different resistivities.

In part $C$ of Figure 4 , resistivity values in both gases increase and overlap below about $70{ }^{\circ} \mathrm{C}$. Above $\mathrm{H} / \mathrm{M}$ and $\mathrm{D} / \mathrm{M}$ ratios of 0.34 , the scattering effect was predominant in relation to $N$ (number of conduction electrons per unit volume): the high concentration of $\mathrm{H}$ and $\mathrm{D}$ atoms mainly operates as a defect point, thus reducing the electrons' mean free path and clearly raising the resistivity. 
It is interesting to observe that the $\rho_{i}$ contribution in the range $25-200{ }^{\circ} \mathrm{C}$ in both isotopes is similar, from a formal point of view, to that observed for a doped semiconductor where the energy distribution of the carriers varies with temperature (usually near $0 \mathrm{~K})$. In region $\mathrm{C}\left(25-70{ }^{\circ} \mathrm{C}\right)$, the resistivity of hydrogenated $\mathrm{Pd}-\mathrm{Ag}$ decreases with $\mathrm{T}^{-3 / 2}(\mathrm{~K})$, following a typical trend for charged impurity scattering in a semiconductor. In the range of temperature from the minimum to the maximum (region $\mathrm{B}$ in Figure 4), the resistivity increases with $\mathrm{T}^{3 / 2}(\mathrm{~K})$, which is a typical trend for lattice vibrational scattering in semiconductors. The manner in which the two scattering mechanisms vary with $\mathrm{T}$ produces the observed minimum. This dependence is only formal because the $\mathrm{Pd}-\mathrm{Ag}$ is not a semiconductor, but gives an idea of how the electronic conductivity of the alloy is complicated and influenced by the loading of isotopes in relation to temperature.

As the main differences in resistivity were observed in the low temperature range $\left(70-200^{\circ} \mathrm{C}\right)$, a slow heating and cooling ramp of temperature $\left(1^{\circ} \mathrm{C} / \mathrm{min}\right)$ was performed in both isotopes in order to verify the effect of exchanging thermal energy on the equilibrium $\mathrm{O}$-sites $\leftrightarrow \mathrm{T}$-sites.

Figure 6 shows that the results in hydrogen were characterized by a clear hysteresis effect, with a higher resistivity when heated. On the contrary, this hysteresis effect on resistivity does not appear in deuterium. In fact, the difference between $\left|\Delta \mathrm{H}_{\mathrm{S}, \mathrm{H}} \mathrm{O}\right|-\left|\Delta \mathrm{H}_{\mathrm{S}, \mathrm{H}}{ }^{\mathrm{T}}\right|$ is higher than that of $\left|\Delta \mathrm{H}_{\mathrm{S}, \mathrm{D}} \mathrm{O}\right|-$ $\left|\Delta \mathrm{H}_{\mathrm{S}, \mathrm{D}} \mathrm{T}\right|$, so that the transition between O-sites and T-sites for hydrogen is characterized by a higher energy barrier. This energy is widely available when moving from high temperature, resulting in lower occupancy and lower resistivity of the cooling curve. On the contrary, moving from low temperature (i.e., heating) the thermal energy needed for the desorption of hydrogen atoms $\left(\left|\Delta \mathrm{H}_{\mathrm{S}, \mathrm{H}} \mathrm{O}\right|-\left|\Delta \mathrm{H}_{\mathrm{S}, \mathrm{H}^{\mathrm{T}}}\right|\right)$ is available only when higher temperatures (corresponding to these needed energy levels) are achieved. Therefore, in the temperature range of the transition tetrahedral $\leftrightarrow$ octahedral, the hydrogen occupancy and resistivity values of the heating curve are higher than those of the cooling curve at a given temperature. Since the difference, $\left|\Delta \mathrm{H}_{\mathrm{S}, \mathrm{H}} \mathrm{O}\right|-\mid \Delta \mathrm{H}_{\mathrm{S}, \mathrm{H}}{ }^{\mathrm{T}}$, is small, the resistivity curve of deuterium does not exhibit a noticeable hysteresis effect.

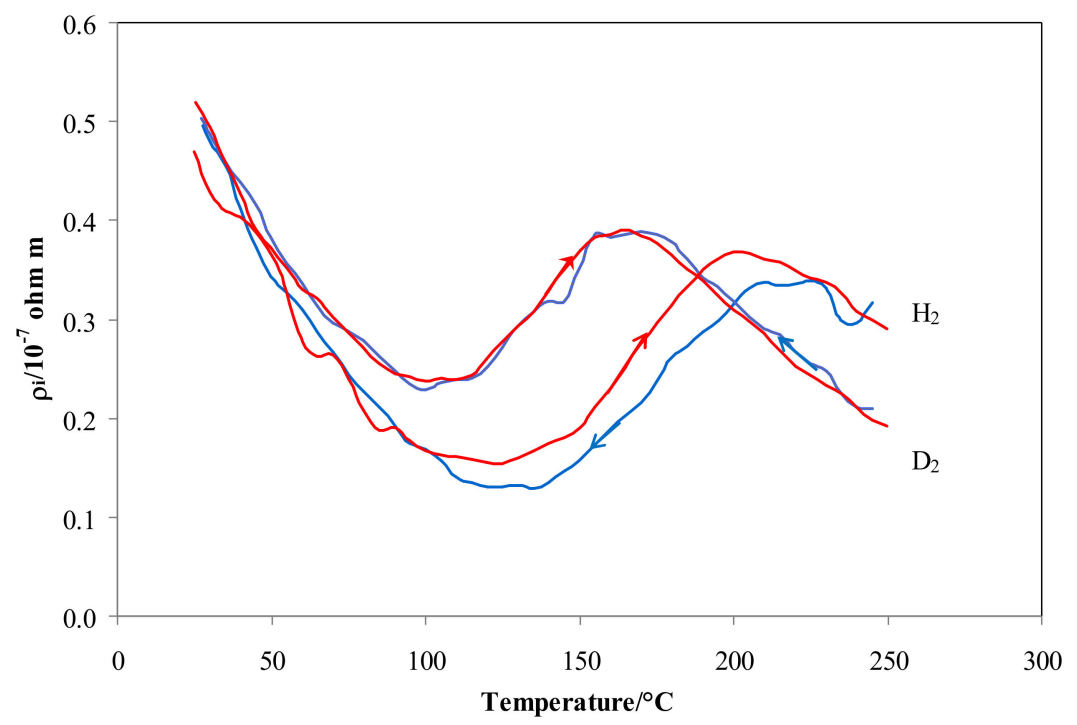

Figure 6. $\rho_{i}$ vs. temperature for Pd-Ag $21 \mathrm{wt}$.\% in pure hydrogen and deuterium. Red lines refer to heating and blue lines to cooling at $1{ }^{\circ} \mathrm{C} \mathrm{min}^{-1}$ and $100 \mathrm{kPa}$.

\section{Conclusions}

The experimental work was aimed at measuring the resistivity of $\mathrm{Pd}-\mathrm{Ag}$ in hydrogen and deuterium at a pressure of $100 \mathrm{kPa}$ and in a temperature range of $25-450{ }^{\circ} \mathrm{C}$. The results showed that electrical resistivity is dependent on the ratio of $\mathrm{H} / \mathrm{M}$ and $\mathrm{D} / \mathrm{M}$. The typical S-shaped behavior of resistivity has been modeled via the free electron theory. The interaction of conduction electrons with hydrogen and deuterium in the Pd-Ag lattice gives rise to different effects: 
- The loading of hydrogen and deuterium atoms at low $\mathrm{H} / \mathrm{M}$ ratios reduces the number of conduction electrons, thereby increasing resistivity,

- $\quad$ Above a well-marked and similar H/M and D/M ratio (about 0.20), the further absorption of isotopes leads to an increase in the conduction electrons, thus reducing the resistivity,

- $\quad$ Further increasing the $\mathrm{H} / \mathrm{M}$ or $\mathrm{D} / \mathrm{M}$ ratio beyond a certain value (about 0.34 ), the electron scattering against the large number of isotope atoms (operating as reticular defects) becomes prevalent, and the resistivity grows very rapidly.

Cooling or heating at a slow rate between $25-250{ }^{\circ} \mathrm{C}$ evidenced a hysteresis effect of resistivity in hydrogen that can be explained by the different energy levels of hydrogen atoms in O-sites and T-sites. Future experiments on hydrogen absorption into Pd-Ag will be addressed to confirm the hysteresis for the curve of $\mathrm{H} / \mathrm{M}$ vs. the temperature via Sievert's law or gravimetric methods.

Author Contributions: For conceptualization, visualization responsible are A.P. and S.T.; investigation, methodology, validation and data analysis were performed by A.P.; writing and editing by A.P. and S.T.; project administration and supervision by S.T.

Funding: This research received no external funding.

Acknowledgments: The authors recognize the contribution of Fabrizio Marini for the design and construction of the experimental setup.

Conflicts of Interest: The authors declare no conflict of interest.

\section{References}

1. Darling, A.S. Thermal and Electrolytic Palladium Alloy Diffusion Cells. Platin. Met. Rev. 1963, 7, 126-129.

2. Medrano, J.A.; Fernandez, E.; Melendez, J.; Parco, M.; Tanaka, D.A.P.; van Sint Annaland, M.; Gallucci, F. Pd-based metallic supported membranes: High-temperature stability and fluidized bed reactor testing. Int. J. Hydrog. Energy 2018, 41, 8706-8718. [CrossRef]

3. Tosti, S.; Pozio, A. Membrane Processes for the Nuclear Fusion Fuel Cycle. Membranes 2018, 8, 96. [CrossRef] [PubMed]

4. Kalyanam, K.; Sood, S. A Comparison of Process Characteristics for the Recovery of Tritium from Heavy Water and Light Water Systems. Fusion Technol. 1988, 14, 524-528. [CrossRef]

5. Cristescu, I.R.; Tamm, U.; Caldwell-Nichols, C.; Glugla, M.; Murdoch, D.; Welte, S. Simultaneous tritium and deuterium transfer in a water detritiation CECE facility at TLK. Fusion Eng. Des. 2003, 69, 109-113. [CrossRef]

6. Albrecht, H.; Hutter, E. Tritium recovery from an ITER ceramic test blanket module-Process options and critical R\&D issues. Fusion Eng. Des. 2000, 49, 769-777.

7. Kinjo, M.; Fukada, S.; Katayama, K.; Edao, Y.; Hayashi, T. Experiment on Recovery of Hydrogen Isotopes from Li 17 Pb 83 Blanket by Liquid-Gas Contact. Fusion Sci. Technol. 2017, 71, 520-526. [CrossRef]

8. Fukada, S.; Nishikawa, T.; Kinjo, M.; Katayama, K. Study of hydrogen recovery from Li-Pb using packed tower. Fusion Eng. Des. 2018, 135, 74-80. [CrossRef]

9. Alpy, N.; Terlain, A.; Lorentz, V. Hydrogen extraction from Pb-17Li: Results with a $800 \mathrm{~mm}$ high packed column. Fusion Eng. Des. 2000, 49, 775-780. [CrossRef]

10. Tosti, S. Membranes and Membrane Reactors for tritium Separation. In Tritium in Fusion: Production, Uses and Environmental Impact; Tosti, S., Ghirelli, N., Eds.; Nova Science Publishers: Hauppauge, NY, USA, 2013; pp. 203-240.

11. Shu, J.; Grandjean, B.P.A.; Van Neste, A.; Kaliaguine, S. Catalytic palladium-based membrane reactors: A review. Can. J. Chem. Eng. 1991, 69, 1036-1060. [CrossRef]

12. Okazaki, J.; Tanaka, D.A.P.; Tanco, M.A.L.; Wakui, Y.; Mizukami, F.; Suzuki, T.M. Hydrogen permeability study of the thin $\mathrm{Pd}-\mathrm{Ag}$ alloy membranes in the temperature range across the $\alpha-\beta$ phase transition. J. Membr. Sci. 2006, 282, 370-374. [CrossRef]

13. Tosti, S.; Borgognoni, F.; Santucci, A. Electrical resistivity, strain and permeability of Pd-Ag membrane tubes. Int. J. Hydrog. Energy 2010, 35, 7796-7802. [CrossRef] 
14. Lewis, F. Hydrogen pressure-hydrogen content and electrical resistance-hydrogen content relationships of palladium and palladium alloy-hydrogen systems. Int. J. Hydrog. Energy 1995, 20, 369-372. [CrossRef]

15. Tosti, S.; Rizzello, C.; Borgognoni, F.; Ghirelli, N.; Santucci, A.; Trabuc, P. Design of Pd-based membrane reactor for gas detritiation. Fusion Eng. Des. 2011, 86, 2180-2183. [CrossRef]

16. Suzuki, Y.; Kimura, S. Separation and concentration of hydrogen isotopes by palladium-alloy membrane. J. Nucl. Sci. Technol. Jpn. 1984, 26, 802-810. [CrossRef]

17. Mitsuishi, N.; Yuki, T.; Ichihara, I. Characteristics of the permeation of hydrogen-inert gas mixtures through a palladium alloy tube wall. J. Less Common Met. 1983, 89, 415-422. [CrossRef]

18. Luo, W.; Cowgill, D.F.; Stewart, K. Absorption isotherms for $\mathrm{H}_{2}\left(\mathrm{D}_{2}\right)-\mathrm{Pd}_{0.8} \mathrm{Ag}_{0.2}$ (198-323 K). J. Alloy. Compd. 2010, 489, 47-50. [CrossRef]

19. Nishiwaka, M.; Shiraishi, T.; Kawamura, Y.; Takeishi, T. Permeation rate of hydrogen isotopes through palladium-silver alloy. J. Nucl. Sci. Technol. 1996, 33, 774-780. [CrossRef]

20. Ackerman, F.J.; Koskinas, G.J. Permeation of Hydrogen and Deuterium through Palladium-Silver. J. Chem. Eng. Data 1972, 17, 51-55. [CrossRef]

21. Lässer, R.; Powell, G. Solubility of protium, deuterium and tritium in palladium-silver alloys at low hydrogen concentrations. J. Less Common Met. 1987, 130, 387-394. [CrossRef]

22. Paolone, A.; Tosti, S.; Santucci, A.; Palumbo, O.; Trequattrini, F. $\mathrm{H}_{2}$ and $\mathrm{D}_{2}$ Solubility in Commercial Pd-Ag Alloys for Hydrogen Purification. ChemEngineering 2017, 1, 14. [CrossRef]

23. Anand, N.S.; Pati, S.; Jat, R.A.; Parida, S.C.; Mukerjee, S.K. Thermodynamics and kinetics of hydrogen/deuterium absorptione desorption in $\mathrm{Pd}_{0.77} \mathrm{Ag}_{0.23}$ alloy. Int. J. Hydrog. Energy 2015, 40, 444-450. [CrossRef]

24. Hickman, R.G. Diffusion and permeation of deuterium in palladium-silver at high temperature and pressure. J. Less Common Met. 1969, 19, 369-383. [CrossRef]

25. Bambakidis, G.; Smith, R.J.; Otterson, D.A. Electrical resisitivity versus Deuterium concentration in Palladium. Phys. Rev. 1969, 177, 1044-1048. [CrossRef]

26. Smith, R.J. Anomalous Electrical Resitivity between 4.2 and $300 \mathrm{~K}$ of Palladium-Deuterium; NASA Technical Note D-2568; National Aeronautics and Space Administration: Washington, DC, USA, 1965.

27. McNicholl, R.A.; Lewis, F.A. Hydrogen contents and electrical resistivity of palladium-Silver alloys. Int. J. Altern. Energy Ecol. 2004, 3, 32-33.

28. Carson, A.W.; Lewis, A.; Schurter, H. Relationships between the Hydrogen Content and Electrical Resistance of Palladium + Silver Alloys. Trans. Faraday Sec. 1967, 43, 1447-1452. [CrossRef]

29. Tóth, J.; Garaguly, J.; Peter, L.; Tompa, K. Resistivity changes during hydrogenation of Pd80Ag20 alloy in non-equilibrium circumstances. J. Alloy. Compd. 2000, 312, 117-120. [CrossRef]

30. Pozio, A.; Jovanović, Z.; Presti, R.L.; De Francesco, M.; Tosti, S. Pd-Ag hydrogen content and electrical resistivity: Temperature and pressure effect. Int. J. Hydrog. Energy 2012, 37, 7925-7933. [CrossRef]

31. Gallagher, P.T.; Oates, W.A. Vibrational entropies of hydrogen in palladium-silver-hydrogen alloys by the isotopic solubility ratio method. J. Phys. Chem. Solids 1971, 322, 2105-2110. [CrossRef]

32. Bourgeois, N.; Crivello, J.-C.; Cenedese, P.; Paul-Boncour, V.; Joubert, J.-M. Vibration analysis of hydrogen, deuterium and tritium in metals: Consequences on the isotope effect. J. Phys. Condens. Matter 2018, 30, 335402. [CrossRef]

33. Geerken, B.M.; Griessen, R.; Huisman, L.M.; Walker, E. Contribution of optical phonons to the elastic moduli of PdHx and PdDx. Phys. Rev. 1982, 26, 1637-1650. [CrossRef]

34. Sonwane, C.G.; Wilcox, J.; Ma, Y.H. Achieving optimum hydrogen permeability in PdAg and PdAu alloys. J. Chem. Phys. 2006, 125, 184714. [CrossRef] [PubMed]

35. Løvvik, O.M.; Olsen, R.A. Density functional calculations on hydrogen in palladium-silver alloys. J. Alloys Compd. 2002, 330, 332-337. [CrossRef]

36. Sicking, G. Isotope effects in metal-hydrogen systems. J. Less Common Met. 1984, 101, 169-190. [CrossRef]

37. Wiswall, R.H.; Reilly, J.J. Inverse Hydrogen Isotope Effects in Some Metal Hydride Systems. Inorg. Chem. 1972, 11, 1691-1696. [CrossRef]

38. Bellini, S.; Sun, Y.; Gallucci, F.; Caravella, A. Thermodynamic Aspects in Non-Ideal Metal Membranes for Hydrogen Purification. Membrane 2018, 8, 82. [CrossRef] [PubMed]

39. Pozio, A.; Jovanović, Z.; Tosti, S. Hydrogen absorption in Pd-Ag system: A TPD and electrical resistivity study. Materials 2019, 12, 3160. [CrossRef] 
40. Serra, E.; Kemali, M.; Perujo, A.; Ross, D.K. Hydrogen and Deuterium in Pd-25 Pct Ag Alloy: Permeation, Diffusion, Solubilization, and Surface Reaction. Metall. Mater. Trans. A 1998, 29, 1023-1028. [CrossRef]

41. Nishiwaka, M.; Shiraishi, T.; Murakami, K. Solubility and Separation Factor of Protium-Deuterium Binary Component System in Palladium. J. Nucl. Sci. Technol. 1996, 33, 504-510. [CrossRef]

42. Brodowsky, H.; Poeschel, E. Wasserstoff in Pd/Ag-Legierungen. Z. Phys. Chem. NF 1965, 44, 143-159. [CrossRef]

43. Millet, P.; Lebouin, C.; Decaux, C.; Ngameni, R.; Ranjbari, A.; Guymont, M. Characterization of metal hydrides using pneumato-chemical impedance spectroscopy. Int. J. Hydrog. Energy 2009, 34, 4990-4996. [CrossRef]

44. Jemaa, N.; Grandjean, B.P.A.; Kaliaguine, S. Diffusion coefficient of hydrogen in a Pd-Ag membrane: Effect of hydrogen solubility. Can. J. Chem. Eng. 1995, 73, 405-410. [CrossRef]

45. Catti, M.; Fabelo, O.; Filabozzi, A.; Pietropaolo, A.; Tosti, S.; Pozio, A.; Santucci, A. Neutron diffraction study of the $\mathrm{Pd}_{0.772} \mathrm{Ag}_{0.228} \mathrm{Dn}$ membrane for hydrogen separation. Int. J. Hydrog. Energy 2017, 42, 6787-6792. [CrossRef]

46. Oriani, R.A. The Physical and Metallurgical Aspects of Hydrogen in Metals. In Proceedings of the Fourth International Conference on Cold Fusion, Lahaina, Maui, HI, USA, 6-9 December 1993; p. 94304.

47. Bickel, P.W.; Berlincourt, T.G. Optical Mode Scattering Contribution to Electrical Resistivity in Zirconium Hydride. Phys. Rev. B 1960, 119, 1603-1604. [CrossRef]

48. Tsuchiya, B.; Teshigawara, M.; Konashi, K.; Nagata, S.; Shikama, T.; Yamawaki, M. Isotope Effects in Thermal Diffusivity and Electrical Resistivity of Zirconium Hydride and Deuteride. J. Nucl. Sci. Technol. 2002, 39, 402-406. [CrossRef]

49. Bickel, P.W.; Berlincourt, T.G. Electrical properties of hydrides and deuterides of zirconium. Phys. Rev. B 1970, 2, 4807-4813. [CrossRef]

50. Tripodi, P.; McKubre, M.; Tanzella, F.; Honnor, P.; Di Gioacchino, D.; Celani, F.; Violante, V. Temperature coefficient of resistivity at compositions approaching PdH. Phys. Lett. A 2000, 276, 122-126. [CrossRef]

51. Rosenberg, H.M. The Solid State, 3th ed.; Oxford Science Publications: Oxford, UK, 1988.

52. Mott, N.F. The Basis of the Electron Theory of Metals, with Special Reference to the Transition Metals. Proc. Phys. Soc. 1949, 62, 416-422. [CrossRef]

53. Fort, D.; Harris, I.R. The physical properties of some palladium alloy hydrogen diffusion membrane material. J. Less Common Metal. 1975, 41, 313-327. [CrossRef] 